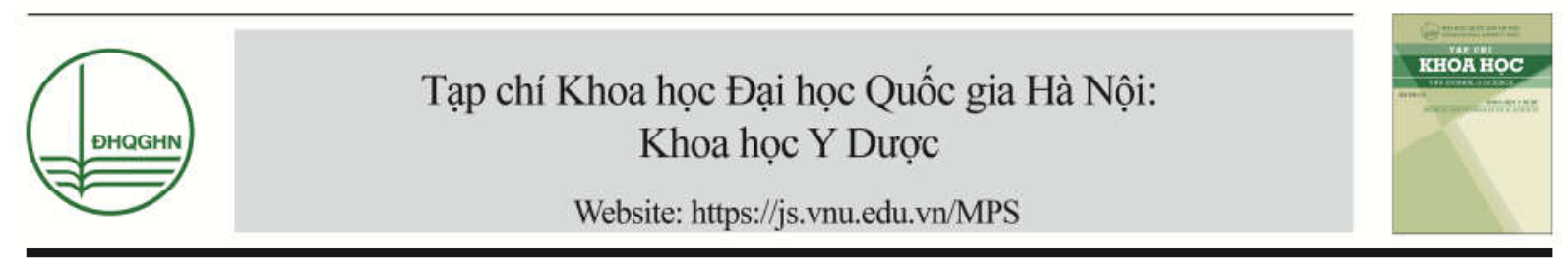

\title{
Sàng lọc in silico, thiết kế phân tử và tổng hợp các hợp chất hóa học có tác dụng ức chế enzym histon deacetylase (HDAC)
}

\author{
Phạm Thế Hải ${ }^{1}$, Nguyễn Hải Nam ${ }^{1}$, Lê Thị Thu Hường ${ }^{2, *}$ \\ ${ }^{1}$ Đại học Dược Hà Nội, 13-15 Lê Thánh Tông, Hà Nội, Việt Nam \\ ${ }^{2}$ Khoa Y duợc, Đại học Quốc gia Hà Nội, 144 Xuân Thủy, Cầu Giấy, Hà Nội, Việt Nam \\ Nhận ngày 06 tháng 02 năm 2018 \\ Chỉnh sửa ngày 24 tháng 4 năm 2018; Chấp nhận đăng ngày 12 tháng 6 năm 2018
}

\begin{abstract}
Tóm tắt: Nghiên cứu thuốc điều trị ung thư mới hiện nay đang là mối quan tâm hàng đầu của thế giới. Một trong số các mục tiêu phân tử đáng chú ý là enzym Histon Deacetylase (HDAC). Hiện nay, khoa học máy tính ngày càng được sử dụng rộng rãi trong tìm kiếm và phát triển thuốc mới. Trong nghiên cứu này, các công cụ máy tính, bao gồm các mô hình liên quan định lượng cấu trúctác dụng (QSAR) và phương pháp mô phỏng phân tử docking đã được sử dụng để thiết kế và sàng lọc nhằm tìm kiếm các hợp chất hoá học mới, có hoạt tính ức chế mạnh enzyme HDAC2, có tiềm năng để phát triển thành thuốc chống ung thư. Kết quả quan trọng nhất của đề tài là đã sàng lọc tìm được 3 nhóm cấu trúc mới, chưa từng được nghiên cứu tác dụng trên đích HDAC cũng như tác dụng kháng ung thư. Trong đó hợp chất acid ibandronic này ức chế $50 \%$ hoạt tính của enzym HDAC chiết từ tế bào ung thư vú ở nồng độ $15 \mu \mathrm{M}$ và có độc tính tế bào mạnh ở mức nồng độ $<50 \mu \mathrm{M}$ trên 3 dòng tế bào ung thư (vú, tiền liệt tuyến và phổi). Ú̉ng dụng phương pháp thiết kế cấu trúc phân mảnh ISIDA, 6 dãy dẫn chất của acid hydroxamic mới được thiết kế. Trong đó hợp chất tích hợp nhân oxoindolin được lựa chọn để tổng hợp và thử hoạt tính ức chế HDAC2. Kết quả cho thấy 3 hợp chất được tổng hợp có hoạt tính ức chế enzym $\mathrm{IC}_{50}$ từ 1,70-6,24 $\mu \mathrm{M}$. Đặc biệt hợp chất 4a có hoạt tính mạnh tương đương với một thuốc ức chế HDAC mạnh hiện đang lưu hành trên thị trường là Vorinostat (SAHA). Nghiên cứu đặc điểm lý hoá cũng như mô phỏng phân tử cho thấy các hợp chất này có đặc điểm giống thuốc phù hợp cho nghiên cứu sâu hơn nhằm phát triển thành thuốc chống ung thư mới trong tương lai.
\end{abstract}

Tù khóa: QSAR, Docking phân tử, chống ung thư, thiết kế thuốc hợp lý, enzym HDAC.

\section{1. Đặt vấn đề}

Theo thống kê của tổ chức $\mathrm{Y}$ tế giới (WHO), ung thư đang trở thành căn bệnh giết

\footnotetext{
* Tác giả liên hệ. ĐT.: 84-24-38387949.

Email: 1tthuong1017@gmail.com

https://doi.org/10.25073/2588-1132/vnumps.4100
}

người hàng đầu thế giới, với khoảng 14 triệu ca mới phát hiện và 8,2 triệu trường hợp tử vong mỗi năm (số liệu tính đến hết năm 2012, theo báo cáo số 297, cập nhật tháng 6 năm 2014). Dự kiến số lượng bệnh nhân mới mắc sẽ tăng lên hơn $70 \%$ trong 2 thập kỷ tới. So với thế giới thì Việt Nam thuộc nhóm nước có tỷ lệ mắc bệnh cao nhất đối với nhiều loại ung thư. Ước 
tính hàng năm tại Việt Nam có khoảng 150-200 nghìn bệnh nhân mới phát hiện mắc ung thư, 70.000 trường hợp tử vong, với $\mathrm{xu}$ hướng gia tăng nhanh trong những năm gần đây.

Trước tình hình đó, việc nghiên cứu và phát triển các thuốc mới chống lại ung thư hiện là mối quan tâm hàng đầu của giới khoa học trong nước cũng như quốc tế. Các thuốc điều trị ung thư hiện đang gặp rất nhiều vấn đề liên quan đến độc tính và tỷ lệ kháng thuốc cao. Do đó yêu cầu cấp bách đặt ra là phải nghiên cứu và phát triển thuốc chống ung thư mới, có tác dụng chọn lọc trên đích phân tử nhằm phát huy tối đa hiệu quả, lâu bị kháng và ít độc hơn.

Qua hơn hai thập kỷ, cùng với sự phát triển vượt bậc của công nghệ sinh học và sinh học phân tử, hàng trăm đích phân tử liên quan đến ung thư đã được phát hiện, phân lập và kiểm chứng. Trong đó, các enzym đóng vai trò quan trọng trong điều hòa chu trình sinh trưởng, phát triển tế bào hiện là đích tác dụng chính mà các thuốc điều trị ung thư hướng đến [1]. Histon deacetylase (HDAC) là một trong những đích phân tử được chú ý hiện nay, enzym này xúc tác cho quá trình deacetyl hoá nhóm $\varepsilon-\mathrm{N}$ acetyl lysine amino acid ở phần đuôi của histon. Trong nhiều tế bào ung thư có sự huy động quá mức các enzym HDAC, gây nên hiện tượng giảm sự acetyl hoá của histon. Các chất ức chế HDAC có thể ngăn chặn quá trình này thông qua việc làm thay đổi biểu hiện gen gây ung thư hay các gen ức chế khối u do gây cường acetyl hóa các protein histone [2]. Hiện nay đã biết đến 18 loại HDAC khác nhau, chia thành 4 nhóm, trong đó HDAC2 thuộc HDAC nhóm I được đánh giá là một trong những đích phân tử quan trọng nhất do có vai trò trong quá trình deacetyl hoá của các histon $\mathrm{H} 3 \mathrm{~K} 56$ và $\mathrm{H} 4 \mathrm{~K} 16$ xảy ra trong hầu hết các dòng tế bào ung thư người $[3,4]$.

Quá trình nghiên cứu tìm kiếm chất ức chế HDAC nhằm phát triển thành thuốc chống ung thư đã kéo dài hơn một thập kỷ [5]. Trong những năm gần đây, nghiên cứu sàng lọc tìm kiếm hay thiết kế hợp chất ức chế HDAC dựa trên các phương pháp trợ giúp bởi máy tính, hay còn gọi là phương pháp in silico đã trở thành một hướng đi mới, đầy tiềm năng và đang được triển khai tại nhiều trung tâm nghiên cứu, trường đại học và công ty dược phẩm hàng đầu trên thế giới [6]. Do đó, nghiên cứu này được thiết kế với 2 mục tiêu: (i) Xác định được các hợp chất hóa học với đặc điểm về cấu trúc hóa học và tương tác phân tử có khả năng ức chế enzyme HDAC in silico; (ii) Thiết kế phân tử và tạo được các cấu trúc hóa học mới, có khả năng ức chế HDAC in vitro.

\section{Xác định các hợp chất hóa học có khả năng ức chế enzyme HDAC in silico}

\subsection{Nguyên liệu và phưong pháp nghiên cưu}

Sàng lọc tìm kiếm hợp chất hóa học có hoạt tính ức chế HDAC2 từ cơ sở dữ liệu (CSDL) Drugbank (https://www.drugbank.ca/) bao gồm 8206 hoạt chất, trong đó có 1991 phân tử có khối lượng nhỏ được cấp đăng ký bởi FDA (cục quản lý Dược phẩm Hoa Kỳ, 207 hợp chất nguồn gốc công nghệ sinh học (protein/peptide) được cấp đăng ký bởi FDA, 93 thực phẩm chức năng và hơn 6000 hoạt chất khác đang trong giai đoạn thử nghiệm. Ứng dụng hai mô hình QSAR về mối quan hệ định lượng giữa cấu trúc hóa học và hoạt tính ức chế HDAC2 đã công bố $[7,8]$, bao gồm:

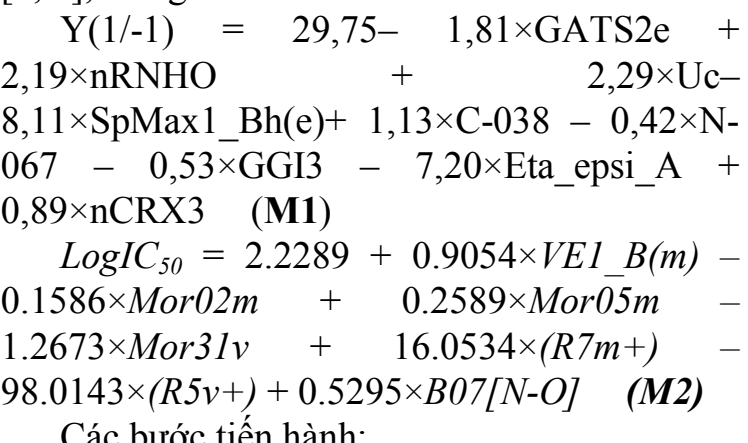

Các bước tiến hành:

Bước 1: Tính toán các tham số phân tử tương ứng trong mô hình $\mathrm{M} 1$ và $\mathrm{M} 2$ cho các hợp chất trong các CSDL DrugBank. Trong đó mô hình M1 nhận giá có hoặc không có tác dụng ức chế HDAC2. Trong nghiên cứu này, 
chọn các chất có $\Delta P \%>0,45$ nhằm lựa chọn các hoạt chất có xác suất rơi vào nhóm có hoạt tính cao hơn.

Bước 2: Áp dụng mô hình M1, chọn lọc các hợp chất dự đoán là có tác dụng ức chế HDAC2.

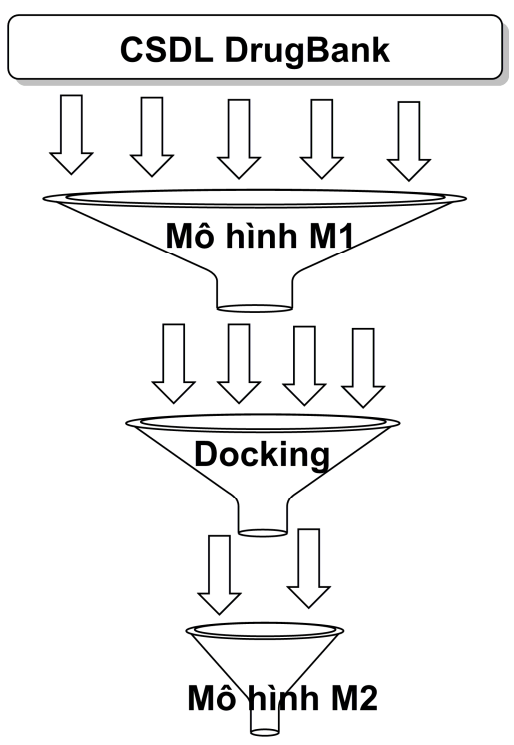

Hình 1. Tóm tắt quy trình sàng lọc in silico chất ức chế HDAC2 từ các thuốc và hợp chất giống thuốc (DrugBank).

Bước 3: Docking các hợp chất này vào phân tử enzym HDAC2. Kiểm tra tương tác giữa các hợp chất này với enzym HDAC2, tính toán năng lượng liên kết ( $\mathrm{kCal} / \mathrm{mol})$, so sánh với một hợp chất có hoạt tính ức chế HDAC2 mạnh là Vorinostat (SAHA).

Bước 4: Áp dụng mô hình M2 cho các hợp chất qua Docking nhằm xác định $\mathrm{IC}_{50}$ của chúng. Xếp thứ tự theo hoạt tính giảm dần ( $\mathrm{IC}_{50}$ tăng).

Bước 5: Chọn từ 3-5 hợp chất tiềm năng nhất sau khi sàng lọc in silico đem thử hoạt tính in vitro và độc tính tế bào.

Thử tác dụng sinh học in vitro bao gồm: (i) Đánh giá tác dụng dược lý ức chế enzym HDAC2 sử dụng Kit định lượng có phát huỳnh quang; (ii) Thử tác dụng ức chế HDAC trên dòng tế bào MCF-7; (iii) Thử độc tính trên 3 dòng tế bào ung thư: tế bào ung thư vú (MCF7), tế bào ung thư tiền liệt tuyến ( $\mathrm{LNCaP})$, tế bào ung thư phổi (SK-LU-1) bằng phương pháp sulforhodamine B (SRB).

\subsection{Kết quả và bàn luận}

Tiến hành sàng lọc 8206 hoạt chất trên cơ sở dữ liệu Drugbank qua sàng lọc bằng các mô hình in silico thu được kết quả như sau:

Áp dụng mô hình M1: thu được 120 hoạt chất dự đoán có tác dụng ức chế HDAC2. Lựa chọn các hợp chất có xác suất hậu nghiệm $Y>$ 0,45 nhằm chọn ra các hợp chất có xác suất có hoạt tính cao hơn.

Áp dụng phương pháp Docking phân tư: thu được 39 hợp chất có khả năng tương tác với trung tâm hoạt động của HDAC2.

Ap dụng mô hình M2: dự đoán được $\mathrm{IC}_{50}$ của 25 hợp chất.

Từ kết quả nêu trên, ba hợp chất đã được chọn để tiến hành thử nghiệm in vitro. Kết quả được biểu diễn trong bảng 1 .

Các kết quả thu được cho thấy quy trình sàng lọc in silico có độ ổn định và chính xác cao. Tất cả các hợp chất được chọn đều thể hiện tác dụng ức chế $\mathrm{HDAC} 2$ với $\mathrm{IC}_{50}$ xác định cho acid ibandronic cao nhất $(46,7 \mu \mathrm{M})$. Hợp chất có tác dụng ức chế HDAC2 cũng có thể có hoạt tính trên các loại HDAC khác qua đó làm tăng tác dụng của các chất. Kết quả cho thấy tác dụng ức chế HDAC trên dòng tế bào ung thư vú (MCF-7) của acid ibandronic mạnh nhất $(15,8$ $\mu \mathrm{M})$. Độc tính tế bào cũng tương ứng với hoạt tính trên HDAC, theo đó acid ibandronic và acid 3-hydroxymyristic có hoạt tính mạnh nhất, đặc biệt là trên dòng tế bào ung thư vú và ung thư phổi.

Tóm lại, một quy trình sàng lọc in silico đã được phát triển thành công và ứng dụng bước đầu trong tìm kiếm cấu trúc mới có khả năng ức chế HDAC2 từ CSDL DrugBank. Kết quả thực nghiệm đã giúp kiểm chứng độ chính xác của quy trình này. 
Bảng 1. Kết quả sàng lọc tìm kiếm hợp chất ức chế $\mathrm{HDAC} 2$ sử dụng các mô hình QSAR

\begin{tabular}{|c|c|c|c|}
\hline Hợp chất được chọn & $\begin{array}{l}\text { Dự đoán } \\
\text { IC }_{50}(\mu \mathrm{M})\end{array}$ & Thực nghiệm $\mathrm{IC}_{50}(\mu \mathrm{M})$ & $\begin{array}{l}\text { Tác dụng dược lý đã biết (Pubchem } \\
\text { Bioasay) }\end{array}$ \\
\hline Acid 3-hydroxymyristic & $\begin{array}{l}69,95 \pm \\
3,25\end{array}$ & $\begin{array}{l}\text { (HDAC2) 61,66 } \pm 5,13 \\
\text { (HDAC) } 25,12 \pm 2,31 \\
(\mathrm{MCF}-7) 34,64 \pm 2,35 \\
(\mathrm{LNCaP}) 47,02 \pm 3,78 \\
\text { (SK-LU-1) 46,77 } \pm 2,83\end{array}$ & $\begin{array}{l}\text { Chất trung gian trong quá trình tổng } \\
\text { hợp axit béo [9], có tác dụng kháng } \\
\text { một số chủng nấm ngoài da như } \\
\text { Kluyveromyces marxianus, Pichia } \\
\text { anomala, Aspergillus nidulans và } \\
\text { Penicillium commune. } \\
\text { Có tác dụng kháng một số chủng vi } \\
\text { khuẩn Gram âm. }\end{array}$ \\
\hline Acid ibandronic & $\begin{array}{l}31,72 \pm \\
2,16\end{array}$ & $\begin{array}{l}\text { (HDAC2) 46,77 } \pm 3,27 \\
(\mathrm{HDAC}) 15,85 \pm 1,12 \\
(\mathrm{MCF}-7) 48,26 \pm 1.34 \\
(\mathrm{LNCaP}) 61,20 \pm 3,67 \\
\text { (SK-LU-1) } 57,19 \pm 3,02\end{array}$ & $\begin{array}{l}\text { Là một thuốc thuộc nhóm } \\
\text { bisphosphonate có chứa gốc } \mathrm{N} \text {, gắn } \\
\text { vào bề mặt xương và ức chế hủy cốt } \\
\text { bào (Hoffman La Roche Inc.). Sử } \\
\text { dụng trong điều trị và ngăn chặn } \\
\text { loãng xương ở phụ nữ mãn kinh. } \\
\text { Ngoài ra ibandronic acid có hiệu quả } \\
\text { ngăn ngừa gãy xương di căn trong đa } \\
\text { u tủy xương, ung thư vú và một số } \\
\text { ung thư khác }[10,11] \text {. }\end{array}$ \\
\hline $\begin{array}{l}\text { Sulfasalazine } \\
\Delta \mathrm{G}=-86,8343(\mathrm{kcal} / \mathrm{mol})\end{array}$ & $\begin{array}{l}80,80 \pm \\
2,71\end{array}$ & $\begin{array}{l}(\mathrm{HDAC}) 128,27 \pm 5,98 \\
(\mathrm{HDAC}) 52,48 \pm 2,35 \\
(\mathrm{MCF}-7) 89,12 \pm 3,51 \\
(\mathrm{LNCaP}) 102,32 \pm 4,78 \\
(\mathrm{SK}-\mathrm{LU}-1) 128,82 \pm 3,19\end{array}$ & $\begin{array}{l}\text { Là một sulfonamid kháng khuẩn, } \\
\text { được chấp thuận là thuốc tại Hoa Kỳ } \\
\text { năm } 1950 \text {. Được sử dụng điều trị } \\
\text { viêm ruột (hiện này ít), bao gồm viêm } \\
\text { loét đại tràng và bệnh Crohn. Ngoài } \\
\text { ra sulfasalazine cũng được chỉ định } \\
\text { trong viêm khớp dạng thấp và một số } \\
\text { trường khớp khác như viêm khớp vẩy } \\
\text { nến. Nghiên cứu tại đại học } \\
\text { Newcastle phát hiện thuốc còn có tác } \\
\text { dụng hô̂ trợ điều trị xơ gan [11]. } \\
\text { Hiện sử dụng nhiều trong điều trị } \\
\text { mày đay tự phát không đáp ứng thuốc } \\
\text { kháng histamin }[12,13] \text {. }\end{array}$ \\
\hline
\end{tabular}

*Năng lượng liên kết với mục tiêu phân tử HDAC2; **Dự đoán nồng độ ức chế $50 \%$ hoạt tính của enzym HDAC2.

\section{Thiết kế phân tử và tổng hợp các cấu trúc mới, có khả năng ức chế HDAC in vitro}

\subsection{Nguyên liệu và phuoong pháp nghiên cưu}

Trong nghiên cứu này khung hydroxamic được lựa chọn làm định hướng thiết kế các hợp chất ức chế HDAC2 mới. Phương pháp thiết kế cấu trúc dựa trên mảnh cấu trúc được áp dụng. Phần mềm ISIDA Fragmentor2015 được áp dụng, sử dụng các kí hiệu dán nhãn mang đặc tính mảnh cấu trúc để xây dựng mô hình QSAR và thiết kế hợp chất mới [14]. Các mảnh cấu trúc được biểu diễn thông qua cơ chế mô tả theo màu (kí hiệu, tính thân dầu, độ $\mathrm{pH} . .$. ) đảm bảo liên quan giữa màu sắc và tính chất hóa học; gán nhãn dựa trên giá trị điện thế và đặc tính dược học. Bước cuối cùng là sử dụng ngôn ngữ lập trình Pascal tìm kiếm và đếm sự có mặt các mảnh cấu trúc đã đánh dấu trong phân tử [15].

Đối với mỗi tập hợp mô tả phân tử, thu được một mô hình tương ứng như sau:

$\operatorname{LogIC}_{50}=1,62+0,13 \times V_{1}-5,41 \times V_{2}-$ $2,05 \times V_{3}+6,47 \times V_{4}+2,01 \times V_{5}+2,18 \times V_{6}+$ $0,25 \times V_{7}-0,16 \times V_{8}$ 
$\operatorname{LogIC}_{50}=1,57-5,59 \times V_{9}-1,02 \times V_{10}-$ $0,91 \times V_{11}+6,19 \times V_{12}+2,50 \times V_{13}-1,54 \times V_{14}+$ $1,06 \times V_{15}-2,04 \times V_{16}$

$\operatorname{LogIC}_{50}=-4,16 \quad-4,35 \times V_{17}-1,37 \times V_{18}$ $+3,34 \times V_{19}+1,56 \times V_{20}+0,49 \times V_{21}-2,33 \times V_{22}+$ $2,42 \times V_{23}-0,33 \times V_{24}$

Các biến $V_{1}-V_{24}$ tương ứng với từng mô hình là vân tay cấu trúc đại diện cho các mảnh cấu trúc được mã hoá thành tham số nhận các giá trị 0 và 1 ứng với sự xuất hiện của chúng trong phân tử (Hình 2).

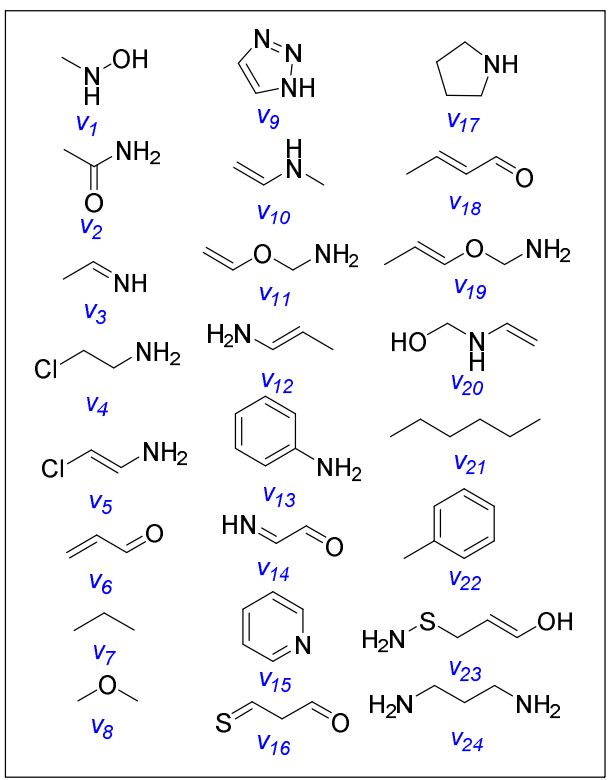

Hình 2. Các mảnh cấu trúc quan trọng được lựa chọn trong mô hình ISIDA1-3 phản ánh mối tương quan định lượng giữa cấu trúc và hoạt tính sinh học ức chế enzyme HDAC2.

\subsection{Kết quả và bàn luận}

Kết hợp cả 3 mô hình, 10 mảnh cấu trúc giữ vai trò quan trọng nhất đóng góp vào hoạt tính ức chế HDAC2 bao gồm $V 2, V 3, V 8, V 9, V 10$, V11, V14, V17, V18, V22 (Hình 2).

Đây là các mảnh cấu trúc được sử dụng trong thiết kế nhóm nhận diện và cầu nối dựa trên cấu trúc cố định nhóm gắn với kẽm acid hydroxamic để tăng cường khả năng gắn kết và hoạt tính ức chế HDAC2. Tổ hợp các mảnh cấu trúc này để tạo thành các hợp chất mới một các tự động bằng Thuật giải di truyền giúp tạo ra hàng nghìn hợp chất [16]. Các khung cấu trúc này được lọc lần thứ nhất bằng việc kiểm tra xem đã từng được công bố chưa bằng cách tìm cấu trúc đồng dạng theo SMILES trên trang webhttps://scifinder.cas.org/.

Bước lọc thứ hai là dự đoán hoạt tính $\left(\mathrm{IC}_{50}\right)$ của các hợp chất được thiết kế bằng chính những mô hình đã xây dựng được.Sử dụng phần mềm ISIDAFragmentor2015tính toán các mô tả phân tử và thay vào các mô hình $\mathbf{M 1}, \mathbf{M 2}$ và M3, lấy trung bình cộng các kết quả dự đoán. Từ các cấu trúc mới đã tính toán, lọc ra các cấu trúc có giá trị $\mathrm{IC}_{50}$ dự đoán tốt và khả thi trong tổng hợp.

Kết quả là thiết kế được cấu trúc mới có tác dụng ức chế HDAC2 tốt nhất (có giá trị $\mathrm{IC}_{50}$ dự đoán thấp nhất $0,3 \mu \mathrm{M}$ ) là $\mathbf{4 a}$.Từ cấu trúc này đề xuất tổng hợp 3 chất với công thức như sau:

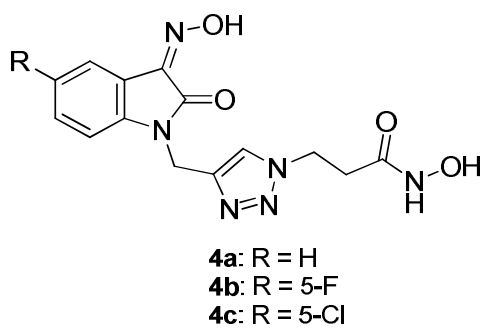

Hình 3. Cấu trúc dẫn xuất acid hydroxamic mới.

Các hợp chất 4a-c đều có khối lượng phân tử $(M W)$ nhỏ hơn 500 dalton, có ít hơn 5 trung tâm cho liên kết hydro $(\mathrm{OH}, \mathrm{NH})(H B d o n)$ và đều có 10 trung tâm nhận liên kết hydro $(H B a c c)(\mathrm{O}, \mathrm{N})$, có giá trị $\log P$ nhỏ hơn 5 và diện tích bề mặt phân cực (TPSA) lớn hơn 75 $\AA^{2}$ và nhỏ hơn $140 \AA^{2}$. Có thể thấy các hợp chất 4a-c có đặc điểm lý hoá phù hợp cho phát triển thành thuốc trong tương lai.

Kết quả docking cho thấy mức độ tương tác tốt trong trung tâm hoạt động của HDAC2, tương tự với kết quả docking của SAHA, 1 thuốc có hoạt tính ức chế HDAC2 mạnh. Cấu dạng 3D của các hợp chất $\mathbf{4 a - c}$ trong trung tâm hoạt động được biểu diễn trong Hình 4. Hợp chất $4 \mathrm{a}$ và $4 \mathrm{c}$ giàu tương tác kỵ nước với các acid amin có tính thân dầu như Phe155, Phe210, Leu276, Tyr209 và Pro34. Hợp chất 4b tạo được nhiều liên kết hydro nhất, sau đó là $\mathbf{4 a}$ 
và $\mathbf{4 c}$. Năng lượng tương tác của $4 \mathbf{c}$ là thấp nhất $(-8,2 \mathrm{kCal} / \mathrm{mol})$, sau đó là $\mathbf{4 a}$ và $\mathbf{4 b}$ cho thấy hợp chất $\mathbf{4 c}$ tạo phức trong protein ổn định nhất so với các hợp chất khác. Tất cả các mức năng lượng của 4a-c đều thấp hơn SAHA. Các phân
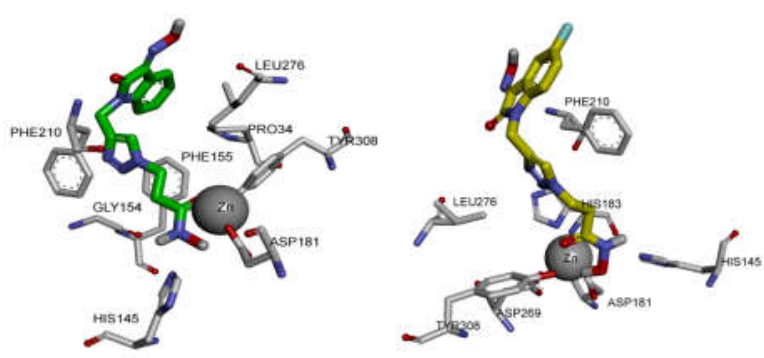

tích này giúp giải thích cơ chế tác dụng cũng như mối liên quan cấu trúc-tác dụng của các hợp chất mới thiết kế.

Quy trình tổng hợp các dẫn xuất này được biểu diễn trong Sơ đồ 5 .

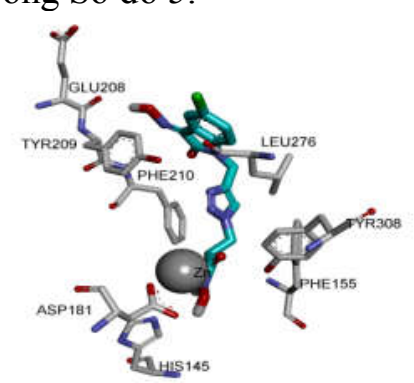

Hình 4. Tương tác giữa 4a (xanh lá), 4b (vàng), 4c (xanh lam) và trung tâm hoạt động của HDAC2.

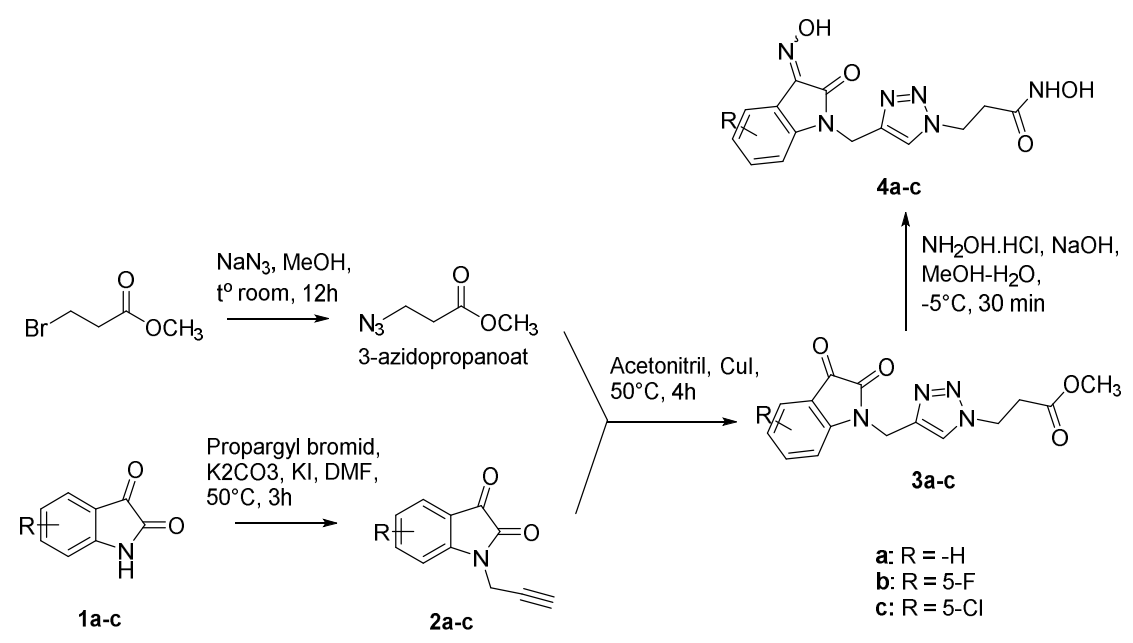

Sơ đồ 1. Quy trình tổng hợp hợp chất mới 4a-c.

Kết quả đã tổng hợp được 3 dẫn chất của acid hydroxamic:

Hợp chất 4a: (N-Hydroxy-3-(4-((3(hydroxyimino)-2-oxoindolin-1-yl)methyl)-1H1,2,3-triazol-1-yl)propanamid.

Chất rắn, màu da cam, khối lượng là $0,21 \mathrm{~g}$, hiệu suất $64,12 \%$, nhiệt độ nóng chảy $187,5-$ $188,5{ }^{\circ} \mathrm{C}, \mathrm{R}_{\mathrm{f}}=0,42(\mathrm{DCM}: \mathrm{MeOH}: \mathrm{AcOH}=$ 90:5:1). ${ }^{1} \mathrm{H}-\mathrm{NMR}\left(500 \mathrm{MHz}, \mathrm{DMSO}-\mathrm{d}_{6}, \mathrm{ppm}\right)$ : $\delta 10,47(1 \mathrm{H}, \mathrm{s}, \mathrm{NH}) ; 8,82(1 \mathrm{H}, \mathrm{s}, \mathrm{OH}) ; 8,02$ (1H, s, H-5'); 7,99 (1H, d, $J=7,0 \mathrm{~Hz}, \mathrm{H}-4$ '); $7,39(1 \mathrm{H}, \mathrm{t}, J=8,0 \mathrm{~Hz}, \mathrm{H}-6 ") ; 7,11(1 \mathrm{H}, \mathrm{t}, J=$ $8,5 \mathrm{~Hz}, \mathrm{H}-5$ "); 7,07 (1H, d, $J=7,5 \mathrm{~Hz}, \mathrm{H}-7$ "); 4,96 (2H, s, H-6'a, H-6’b); 4,51 (2H, t, $J=7,0$
$\mathrm{Hz}, \mathrm{H}-3 \mathrm{a}, \mathrm{H}-3 \mathrm{~b}) ; 2,57$ (2H, t, $J=7,0 \mathrm{~Hz}, \mathrm{H}-2 \mathrm{a}$, $\mathrm{H}-2 \mathrm{~b})$. FAB-MS m/z: 353,1001 [M+Na] .

Hợp chất 4b: 3-(4-((5-Fluoro-3(hydroxyimino)-2-oxoindolin-1-yl)methyl)-1H1,2,3-triazol-1-yl)-N-hydroxypropanamid

Chất rắn, màu da cam, khối lượng là $0,22 \mathrm{~g}$, hiệu suất $63,15 \%$, nhiệt độ nóng chảy $187,5-$ $188,5{ }^{\circ} \mathrm{C}, \mathrm{R}_{\mathrm{f}}=0,41(\mathrm{DCM}: \mathrm{MeOH}: \mathrm{AcOH}=$ 90:5:1). ${ }^{1} H-N M R\left(500 \mathrm{MHz}, \mathrm{DMSO}-d_{6}, \mathrm{ppm}\right): \delta$ 10,38 (1H, s, NH); 8,05 (1H, s, H-5'); 7,74 (1H, dd, $J=8,0 \mathrm{~Hz}, J^{\prime}=2,0 \mathrm{~Hz}, \mathrm{H}-4$ "'); 7,28 (1H, td, $J=8,5 \mathrm{~Hz}, J^{\prime}=2,0 \mathrm{~Hz}, \mathrm{H}-6$ "); 7,13 (1H, dd, $J$ $=8,5 \mathrm{~Hz}, J^{\prime}=4,0 \mathrm{~Hz}, \mathrm{H}-7$ "); 4,97 (2H, s, H6'a, H-6'b); 4,53-4,48 (2H, m, H-3a, H-3b); 
$2,86(1 \mathrm{H}, \mathrm{t}, J=6,75 \mathrm{~Hz}, \mathrm{H}-2 \mathrm{a}) 2,57(2 \mathrm{H}, \mathrm{t}, J=$ $6,75 \mathrm{~Hz}, \mathrm{H}-2 \mathrm{~b})$. FAB-MS m/z: 347,0897 [M-H] ${ }^{-}$.

Hợp chất 4c: 3-(4-((5-Cloro-3(hydroxyimino)-2-oxoindolin-1-yl)methyl)-1H1,2,3-triazol-1-yl)-N-hydroxypropanamid.

Chất rắn, màu da cam, khối lượng là $0,23 \mathrm{~g}$, hiệu suất $63,21 \%$, nhiệt độ nóng chảy 187,0 $189,0{ }^{\circ} \mathrm{C},{ }^{1} \mathrm{H}-\mathrm{NMR}\left(500 \mathrm{MHz}, \mathrm{DMSO}-\mathrm{d}_{6}, \mathrm{ppm}\right)$ : $\delta 14,70(1 \mathrm{H}, \mathrm{s}, \mathrm{NH}) ; 10,48(1 \mathrm{H}, \mathrm{s}, \mathrm{NH}) ; 8,83$ $(1 \mathrm{H}, \mathrm{s}, \mathrm{OH}) ; 8,03(1 \mathrm{H}, \mathrm{s}, \mathrm{H}-5$ '); 7,96 (1H, d, $J=$ $1,75 \mathrm{~Hz}, \mathrm{H}-4$ "); 7,48 $\left(1 \mathrm{H}, \mathrm{dd}, J=8,5 \mathrm{~Hz}, J^{\prime}=\right.$ $1,75 \mathrm{~Hz}, \mathrm{H}-6$ "); 7,14 (1H, d, $J=8,5 \mathrm{~Hz}, \mathrm{H}-7$ "); 4,98 (2H, s, H-6'a, H-6'b); 4,52 (2H, t, $J=6,75$ $\mathrm{Hz}, \mathrm{H}-3 \mathrm{a}, \mathrm{H}-3 \mathrm{~b}) ; 2,57$ (2H, t, $J=6,75 \mathrm{~Hz}, \mathrm{H}-$ 2a, H-2b). FAB-MS m/z: 365,0754 [M+H] .

Các dẫn chất 4a-c được thử tác dụng ức chế HDAC2 theo phương pháp huỳnh quang. Kết quả được trình bày trong bảng dưới đây.

Bảng 2. Kết quả thử tác dụng ức chế HDAC của các dẫn chất $4 \mathrm{a}-\mathrm{c}$

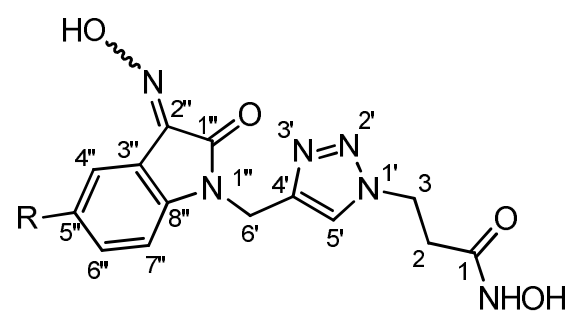

\begin{tabular}{lll}
\hline Chất & $\mathrm{R}$ & $\begin{array}{l}\mathrm{HDAC2} \mathrm{IC}_{50} \\
(\mu \mathrm{g} / \mathrm{ml})\end{array}$ \\
\hline $4 \mathrm{a}$ & $\mathrm{H}$ & $0,56 \pm 0,77$ \\
$4 \mathrm{~b}$ & $5-\mathrm{F}$ & $2,17 \pm 1,98$ \\
4c & $5-\mathrm{Cl}$ & $1,02 \pm 0,56$ \\
SAHA & $0,28 \pm 0,03$ \\
\hline
\end{tabular}

Kết quả thu được trong Bảng 2 cho thấy các dẫn chất tổng hợp được có $\mathrm{IC}_{50}$ từ $0,28-2,17$ $\mu \mathrm{g} / \mathrm{ml}$. Như vậy, các chất tổng hợp được, đặc biệt là chất $\mathbf{4 a}$, có hoạt tính ức chế HDAC2 tương đối tốt (tương đồng với SAHA, chất đối chứng). Hoạt chất $\mathbf{4 a}$ có thể trở thành hợp chất dẫn đường tiềm năng mới, phát triển thành thuốc chữa ung thư.

\section{Kết luận và Kiến nghị}

Các kết quả của đề tài cho thấy phương pháp nghiên cứu sàng lọc ảo cũng như thiết kế hợp lý thuốc dựa trên tính toán (in silico) là một hướng đi rất tiềm năng trong tìm kiếm các hoạt chất có tác dụng dược lý mong muốn, cũng như trong định hướng các nghiên cứu phát triển thuốc hướng đích. Quy trình sàng lọc ảo kết hợp thử hoạt tính sinh học in vitro đã được xây dựng thành công trong nghiên cứu này và hoạt động với độ ổn định và chính xác cao. Ngoài ra đề tài đã phát triển một phương pháp tổ hợp mảnh cấu trúc ISIDA giúp thiết kế số lượng lớn các dẫn xuất của acid hydroxamic và đánh giá tự động hoạt tính ức chế enzym HDAC2, giúp tìm kiếm và tối ưu hoá hợp chất dẫn đường mới mang khung cấu trúc acid hydroxamic định hướng cho tổng hợp thuốc điều trị ung thư mới. Nghiên cứu đã tổ hợp 10 mảnh cấu trúc trên nền khung acid hydroxamic nhằm tạo ra một số khung dẫn xuất mới, được dự đoán là có tác dụng ức chế mạnh trên HDAC2. Đặc biệt nghiên cứu này đề xuất khung cấu trúc dẫn chất 4a được với hoạt tính mạnh, có đặc điểm hoá học không quá khó để tổng tợp, là tiền đề cho các nghiên cứu tìm kiếm hợp chất dẫn đường mới trong tương lai.

Để có thể phát triển và sử dụng rộng rãi quy trình sàng lọc in silico-in vitro cũng như phương pháp thiết kế cấu trúc mảnh ISIDA, đề tài xin kiến nghị một số nội dung:

Xây dựng phần mềm (hệ chuyên gia, expert system) tích hợp các mô hình QSAR một cách đơn giản để người dùng có thể sử dụng trong sàng lọc và tìm kiếm hợp chất ức chế HDAC2 mới từ các cơ sở dữ liệu khác. Mở rộng đối tượng tìm kiếm như cơ sở dữ liệu các hợp chất thiên nhiên Việt Nam, các hợp chất khác trong cơ sở dữ liệu lớn hơn như Pubchem, ChEMBL, hay ZINC...

Tiếp tục nghiên cứu tối ưu hoá và tổng hợp các dẫn chất của acid hydroxamic mới, nhằm tăng hoạt tính ức chế HDAC2 của các khung cấu trúc tìm được. Tiến hành các nghiên cứu tiền lâm sàng, độc tính tế bào in vitro, tác dụng 
ức chế khối u rắn sử dụng mô hình in vivo, và các nghiên cứu thực nghiệm xác định tính thấm, khả năng chuyển hoá và độc tính của các chất tìm được.

\section{Lời cảm ơn}

Nghiên cứu được thực hiện trong khuôn khổ Đề tài khoa học và công nghệ cấp ĐHQGHN, mã số QG.16.24.

\section{Tài liệu tham khảo}

[1] C. Avendaño, J.C. Menéndez. Chapter 13 - Drug Targeting in Anticancer Chemotherapy. In: Menéndez CAC (ed) Medicinal Chemistry of Anticancer Drugs (Second Edition). Elsevier, Boston, (2015) 595.

[2] S.Y. Roth, et al., Histone acetyltransferase. Annual review of biochemistry, 70 (2001) 81.

[3] P. Bertrand, Inside HDAC with HDAC inhibitors. European journal of medicinal chemistry 45 (2010) 116.

[4] M. Claude, Histone deacetylase inhibitors. European journal of medicinal chemistry 40 (2005) 1.

[5] L. Zhang, et al., Strategies in developing promising histone deacetylase inhibitors. Medicinal Research Reviews 30 (2010) 585.

[6] C. Nicola, et al., Chapter One - Recent Advances in Cancer Therapeutics. In: Lawton G, Witty DR (eds) Progress in Medicinal Chemistry, vol 54. Elsevier, (2015) 1.

[7] H. Pham-The, et al., Quantitative structureactivity relationship analysis and virtual screening studies for identifying HDAC2 inhibitors from known HDAC bioactive chemical libraries. SAR and QSAR in Environmental Research 28 (2017) 199.

[8] H. Pham-The, H. Le-Thi-Thu. Integrating Structure and Ligand-Based Approaches for Modelling the Histone Deacetylase inhibition activity of Hydroxamic Acid derivatives. Asian Journal of Pharmaceutical and Clinical Research 11 (2018) 199.

[9] D. Kirschner, et al., Method for detecting the 3hydroxymyristic acid component of the endotoxins of gram-negative bacteria in compost samples. American Industrial Hygiene Association 46 (1985) 741.

[10] F. Bauss. Ibandronate: the first once-monthly oral bisphosphonate for treatment of postmenopausal osteoporosis. Therapeutics and Clinical Risk Management 2 (2006) 3

[11] H. B. Sittig, Pathogenesis and bisphosphonate treatment of skeletal events and bone pain in metastatic cancer: focus on ibandronate. Onkologie 35 (2012) 380.

[12] L. Y. McGirt, et al. Successful treatment of recalcitrant chronic idiopathic urticaria with sulfasalazine. Archives of Dermatology 142 (2006) 1337

[13] N. Weidner, et al. Sulfasalazine in treatment of collagenous colitis. Case report and review of the literature. American Journal of Medicine 77 (1984) 162.

[14] A. Varnek, et al., ISIDA - Platform for Virtual Screening Based on Fragment and Pharmacophoric Descriptors. Current ComputerAided Drug Design 4 (2008) 191.

[15] V. Consonni and D. Ballabio, Comments on the definition of the $Q^{2}$ parameter for QSAR validation. Journal of Chemical Information and Modeling 49 (2009) 1669.

[16] N.T.T. Hoài and P.T.T.Q. Chiến, Thuật giải di truyền và ứng dụng. Tuyền tập Báo cáo Hội nghị Sinh viên nghiên cứu khoa học lần thứ 6 (2008) 266. 


\title{
In Silico Screening, Design and Synthesis of Novel Inhibitors against Histone Deacetylase (HDAC)
}

\author{
Pham The Hai ${ }^{1}$, Nguyen Hai Nam ${ }^{1}$, Le Thi Thu Huong ${ }^{2}$ \\ ${ }^{1}$ Hanoi University of Pharmacy, 13-15 Le Thanh Tong, Hanoi,Vietnam \\ ${ }^{2}$ VNU School of Medicine and Pharmacy, 144 Xuan Thuy, Cau Giay, Hanoi, Vietnam
}

\begin{abstract}
Finding a new treatment for cancer is one of the most interested fields for pharmaceutical research worldwide. As a member of HDAC class I, histone deacetylase 2 (HDAC2) appears to be an important druggable target. Today, computer-aided drug design is increasingly used in the drug discovery and development processes. In this study, computational methods, including Quantitative Structure-Activity Relationship and Molecular Docking approaches, have been explored for virtual screening as well as rational design of potential inhibitors of HDAC enzymes. The main results included the identification of 3 novel structure scaffolds, which had never been studied in antiHDAC or anticancer activities. In particular, ibandronic acid showed very good half-maximal inhibitory concentration against HDAC extracted from MCF-7 cell line $\left(\mathrm{IC}_{50}\right.$ of $\left.15 \mu \mathrm{M}\right)$ and citotoxicity of $<50 \mu \mathrm{M}$ against three cancer cell lines (MCF-7, LNCaP, and SK-LU-1). On the other hand, six novel series of HDAC2 inhibitors were rationally designed using molecular descriptors derived from ISIDA fragmentor methodology. A series of novel hydroxamates incorporating oxoindoline aromatic system was synthesized and evaluated in the inhibitory activity against HDAC2 enzyme. The results showed that three synthesized compounds (4a-c) exhibited very good inhibitory potency, with $\mathrm{IC}_{50}$ ranged from 1.70-6.24 $\mu \mathrm{M}$; notably, compound 4a displayed similar potency to that of Vorinostat (SAHA), a commercial drug currently used in the management of cutaneous $\mathrm{T}$ cell lymphoma. Physicochemical and molecular simulation profiling assays suggested that this compound was drug-like and suitable for further study towards developing it into new anti-cancer drug.
\end{abstract}

Keywords: QSAR, Molecualr Docking, anticancer, rational drug design, HDAC. 